\title{
Biological Science in Oregon
}

\section{Fishing is an important part of \\ Oregon's culture. The Western Fisheries Research Center (WFRC) has been conducting research in Oregon for many years to provide information that can be used by managers to help keep fish and other parts of the ecosystem healthy. Below are examples of some of WFRC's studies.}

\section{If You Build It, Will They Come?}

Crims Island in the lower Columbia River is shaping up to be a "Field of Dreams" for juvenile salmon. Young salmon use tidal marsh habitats to grow and prepare themselves for entering the sea. However, most of the marsh habitat on Crims Island was ditched and drained to allow for farming and cattle grazing leaving fish with only a straight, narrow ditch with slumping banks.

Now, 70 years later, efforts are under way to restore marsh habitat to its original condition. In 2005, the U.S. Army Corps of Engineers used a fleet of earthmoving equipment to dig new tidal channels and rearrange over 90 acres to provide a better home for young salmon. The WFRC is monitoring fish habitat use and food availability before and after the restoration. Also, by using

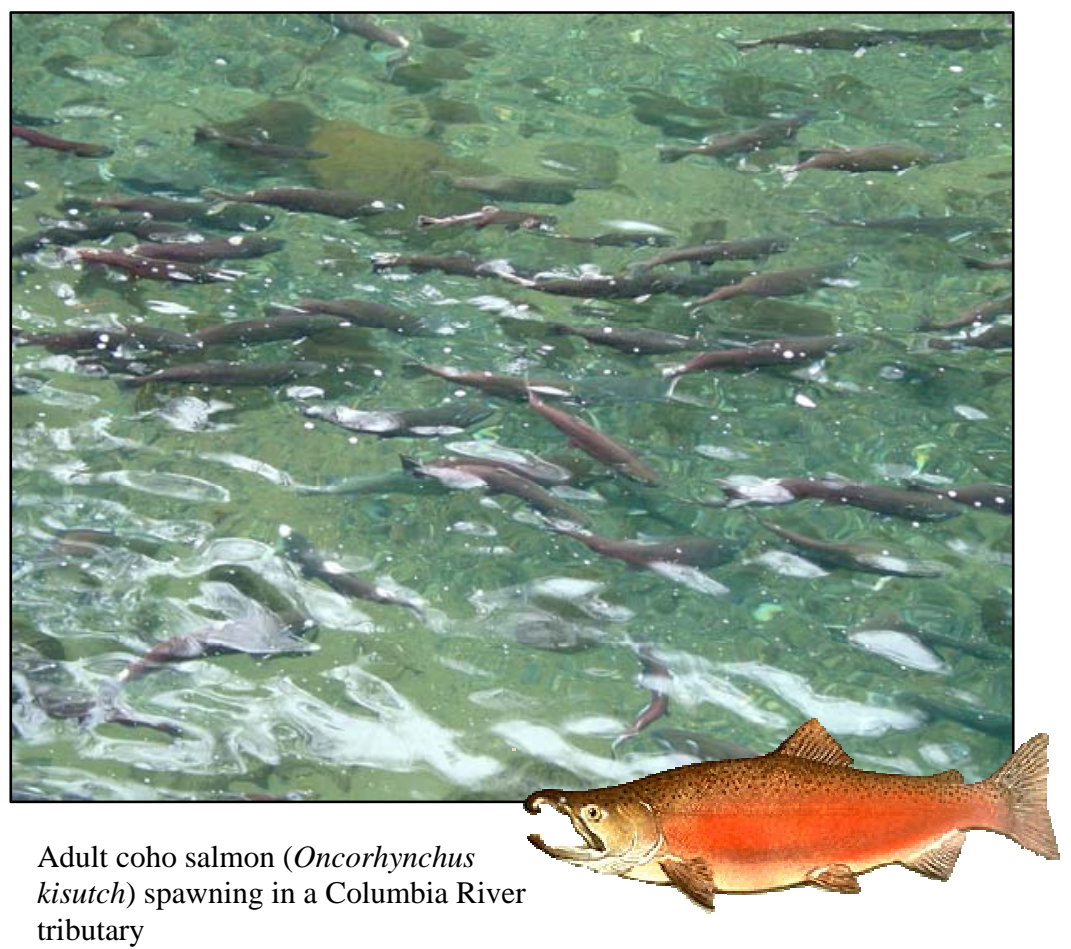

small pumps to flush food from the fish's stomachs, the amounts and kinds of food eaten will be compared to what is available in the water. This information will tell scientists if the new marsh habitat produces the high-quality food that salmon need for good growth in their new home. The information produced by this study will guide other habitat restoration projects in the lower Columbia River estuary.

\section{Helping Recover Salmon in the WillametteValley}

As we work to increase the number of salmon in our rivers it is important to consider the quality of the water. Although most of the rivers in Oregon are clear and crisp, poor water quality does impact aquatic animals in some areas of the state. Poor water quality can be in the form of high temperatures, low oxygen, or chemicals from human activities in urban and rural areas.

To help managers develop plans to recover salmon, WFRC scientists have developed a computer program (using a Geographic Information System, or GIS) that combines all of the available water quality information for the Willamette and lower Columbia rivers, and the tributaries and streams that feed them. This decision support tool will allow managers to decide where there are the most serious water quality problems and to direct habitat restoration efforts to where they will most help recover salmon. 
Swimming Against the Currents of Change - Dams, Reservoirs, and White Sturgeon Spawning

White sturgeon (Acipenser transmontanus) attract attention because of their large size and prehistoric looks. People in Oregon enjoy fishing for sturgeon, watching them breach and roll in the river, and viewing them in aquariums where they are displayed. What they don't often consider is that every one of these large fish began life as an egg about the size of a pearl. Although harvest of these magnificent fish has been regulated since the 1950s, it wasn't until the mid-1980s that studies were conducted to determine where and when white sturgeon spawn. Since then, we have determined that white sturgeon spawn mainly during May and June in very fast flowing waters such as in areas immediately downstream from most dams.

\section{In the Columbia River, WFRC} scientists measure the level of success of spawning by looking for small juvenile white sturgeon in

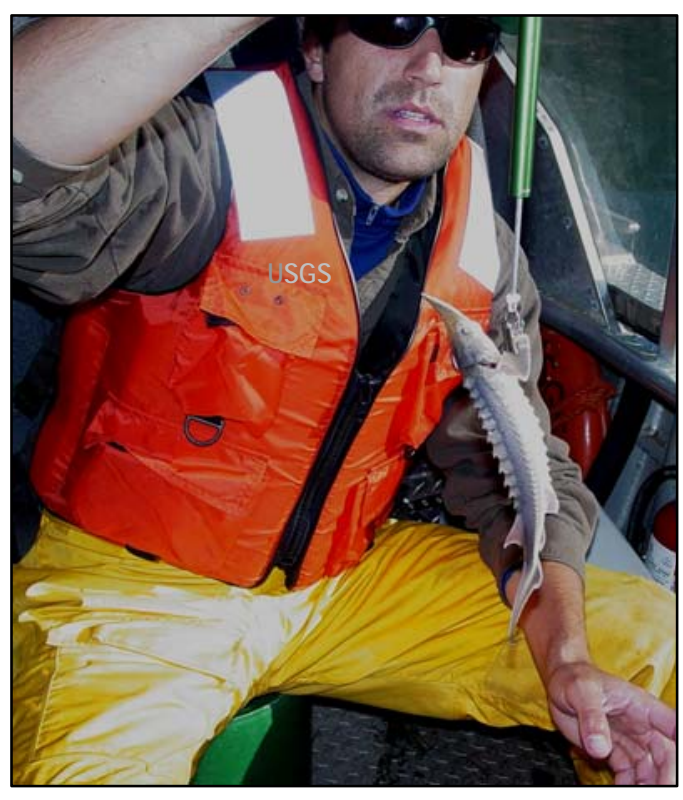

Weighing a juvenile (about 4 months old) white sturgeon from the Columbia River

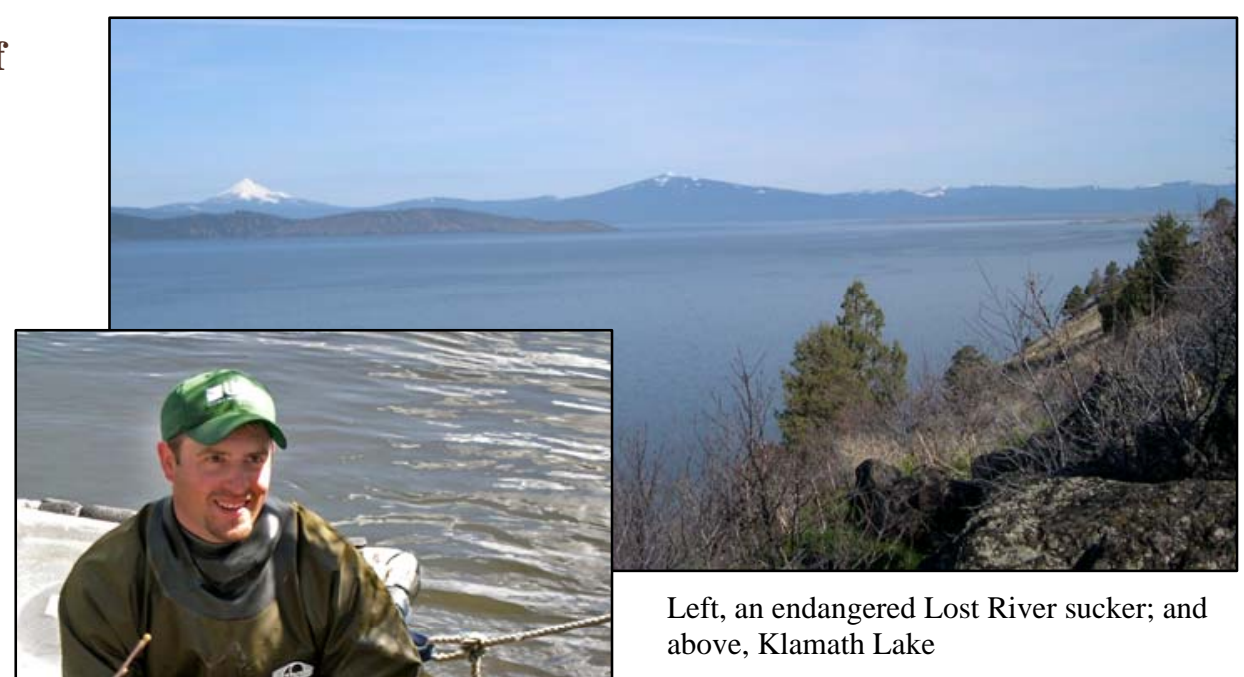

has conducted research in this basin since the mid-1980s. Most of the research at the KFFS is conducted on two species of federally endangered Upper Klamath Lake fishes, the Lost River (Deltistes luxatus) and shortnose suckers (Chasmistes brevirostris). Studies focus on understanding the life history requirements, assessing status and trends of populations, habitat use, behavioral ecology, and population dynamics of sucker populations.

The KFFS staff works closely with personnel from the USGS Oregon Water Science Center, which conducts studies examining various aspects of hydrology and water quality in the Upper Klamath Basin. The close association allows for a multidisciplinary understanding of the Upper Klamath Basin ecosystem as a whole and enhances the studies conducted. The KFFS also works with managers from state and federal agencies and tribes to ensure information being collected is applicable to species recovery efforts.

For additional information, please contact:

Lyman Thorsteinson, Center Director U.S. Geological Survey Western Fisheries Research Center 6505 NE $65^{\text {th }}$ Street, Seattle, WA 98115 (206) 526-6282 ext. 236; FAX (206) 5266654; http://wfrc.usgs.gov 